\title{
Metabolic Adaptation of the Fetal and Postnatal Ovine Heart: Regulatory Role of Hypoxia-Inducible Factors and Nuclear Respiratory Factor-1
}

\author{
PETER N. NAU, TIMOTHY VAN NATTA, J. CARTER RALPHE, CYNTHIA J. TENEYCK, \\ KURT A. BEDELL, CHRISTOPHER A. CALDARONE, JEFFREY L. SEGAR, AND
}

THOMAS D. SCHOLZ

Department of Pediatrics [P.N.N., J.C.R., C.J.T., K.A.B., J.L.S., T.D.S.], Department of Surgery [T.V.N., C.A.C.], Division of Pediatric Cardiology, University of Iowa, Iowa City, Iowa, U.S.A.

\begin{abstract}
Numerous metabolic adaptations occur in the heart after birth. Important transcription factors that regulate expression of the glycolytic and mitochondrial oxidative genes are hypoxiainducible factors (HIF-1 $\alpha$ and $-2 \alpha$ ) and nuclear respiratory factor-1 (NRF-1). The goal of this study was to examine expression of HIF- $1 \alpha$, HIF- $2 \alpha$, and NRF-1 and the genes they regulate in pre- and postnatal myocardium. Ovine right and left ventricular myocardium was obtained at four time points: 95 and $140 \mathrm{~d}$ gestation (term $=145 \mathrm{~d}$ ) and $7 \mathrm{~d}$ and 8 wk postnatally. Steadystate mRNA and protein levels of HIF- $1 \alpha$ and NRF-1 and protein levels of HIF- $2 \alpha$ were measured along with mRNA of HIF- $1 \alpha$ regulated genes (aldolase $\mathrm{A}, \alpha$ - and $\beta$-enolase, lactate dehydrogenase A, liver and muscle phosphofructokinase) and NRF-1regulated genes (cytochrome $c$, Va subunit of cytochrome oxidase, and carnitine palmitoyltransferase I ). HIF- $1 \alpha$ protein was present in fetal myocardium but dropped below detectable levels at $7 \mathrm{~d}$ postnatally. HIF- $2 \alpha$ protein levels were similar at the four time points. Steady-state mRNA levels of $\alpha$-enolase, lactate dehydrogenase $\mathrm{A}$, and liver phosphofructokinase declined significantly postnatally. Aldolase A, $\beta$-enolase, and muscle phosphofructokinase mRNA levels increased postnatally. Steady-
\end{abstract}

\section{ABSTRACT}

state mRNA and protein levels of NRF-1 decreased postnatally in contrast to the postnatal increases in cytochrome $c$, subunit $\mathrm{Va}$ of cytochrome oxidase, and carnitine palmitoyltransferase I mRNA levels. The in vivo postnatal regulation of enzymes encoding glycolytic and mitochondrial enzymes is complex. As transactivation response elements for the genes encoding metabolic enzymes continue to be characterized, studies using the fetal-to-postnatal metabolic transition of the heart will continue to help define the in vivo role of these transcription factors. (Pediatr Res 52: 269-278, 2002)

Abbreviations
HIF-1 $\alpha$, hypoxia-inducible factor- $1 \alpha$
HIF-2 $\alpha$, hypoxia-inducible factor- $2 \alpha$
PFK-L, phosphofructokinase, liver isoform
PFK-M, phosphofructokinase, muscle isoform
LDH A, lactate dehydrogenase A
NRF, nuclear respiratory factor
COX Va, cytochrome oxidase, subunit Va
CPT I, carnitine palmitoyltransferase I

After the transition to postnatal life, the cardiac myocyte faces a dramatic change in oxygen availability and substrate selection. Fetal oxidation of glucose and lactate via glycolysis for energy production shifts after birth toward an increased reliance on fatty acids, which provide the major source of fuel in the adult heart (1). The number and complexity of mitochondria also increases after birth, as the heart shifts from a

Received August 28, 2001; accepted March 5, 2002.

Correspondence: Thomas D. Scholz, M.D., Division of Pediatric Cardiology, 2852 JPP, University of Iowa, 200 Hawkins Drive, Iowa City, IA 52242; e-mail: thomas-scholz@uiowa.edu

Supported by Grants R29 HL56633 (T.D.S.) and RO1 HL64770 (J.L.S.) from the National Institutes of Health.

DOI: 10.1023/01.PDR.0000023174.89966.D7 reliance on glycolytic pathways to increased flux through mitochondrial oxidative reactions (2). The mechanisms that coordinate the complex metabolic response within the cardiac myocyte are just beginning to be elucidated.

HIF-1 and -2 , recently described transcription factors, may play an important role in regulating the postnatal metabolic response $(3,4)$. HIF-1 was initially identified as a primary transcription factor for the erythropoietin gene in hepatocellular carcinoma cells that were made hypoxic in culture (5). In its active form, HIF- 1 exists as a heterodimer of HIF- $1 \alpha$ and $-1 \beta$, both of which contain basic helix-loop-helix and PER-aryl hydrocarbon nuclear translocator-SIM (PAS) domains (6). HIF- $2 \alpha$ (also referred to as endothelial PAS domain protein 1, or EPAS1) was identified through database searches for ana- 
logues to HIF- $1 \alpha(7,8)$. The regulatory functions of both HIF- $1 \alpha$ and $-2 \alpha$ appear to be mediated by binding to a hypoxia response element that can be located within or adjacent to the target gene in the 5'- or 3'-flanking sequences $(6,8,9)$. The range of target genes activated by HIF- $1 \alpha$ continues to grow and includes important glycolytic enzymes such as aldolase A, $\alpha$-enolase, glyceraldehyde phosphate dehydrogenase, hexokinase, PFK-L, and LDH A (10-13). Thus, through changes in glycolytic enzyme content in the cardiac myocyte, HIF- $1 \alpha$ can increase the $V_{\max }$ of substrates through glycolysis and the subsequent delivery of reducing equivalents and acetyl CoA to the mitochondria.

The cardiac mitochondrial response to development or disease is necessarily complex, because a change in the mitochondria number or an alteration in mitochondrial enzyme proportions requires a coordinated response of both the nuclear and mitochondrial genomes. Studies to understand the transcriptional control of these geographically separate DNA pools are increasing. NRF are an important family of transcription factors recently identified that regulate gene expression in both the nucleus and mitochondria (14-16). Two trans-acting NRF, designated NRF-1 and -2, have been defined (16). Studies of the regions upstream from the cytochrome $c$ gene identified the NRF-1 binding site (14) and studies on cytochrome oxidase IV yielded several peptides that were associated with its regulatory region, the primary DNA-binding protein being designated NRF-2 (17). Both NRF-1 and -2 regulate nuclear DNA transcription $(15,16)$. Activation of nuclear encoded genes that regulate mitochondrial DNA transcription, such as mitochondrial RNA processing endonuclease and mitochondrial transcription factor $\mathrm{A}$, led to the conclusion that the NRF-1 plays a role in coordinating transcription in both the nuclear and mitochondrial genomes. Important studies by Xia et al. (18) defined the temporal relationship between NRF-1 expression and up-regulation of COX Va and the muscle isoform of CPT I in electrically stimulated myocytes. These studies suggested that NRF-1 may coordinate the response of several nuclear encoded mitochondria proteins in physiologically important situations.

It is clear that a variety of complex regulatory mechanisms act in the developing heart to orchestrate the rapid adaptive changes that must occur in the transition to postnatal life. However, little is know about the ontogeny of important transcription factors such as HIF- $1 \alpha$ and $-2 \alpha$, and NRF-1 in mammalian cardiac myocytes. Furthermore, transcriptional control of the genes encoding key glycolytic and oxidative enzymes has not been extensively studied. The goal of the current investigation was to determine the fetal and postnatal changes in HIF- $1 \alpha$ and $-2 \alpha$, and NRF-1 at the mRNA and protein levels. In addition, steady-state mRNA levels of metabolic enzymes thought to be regulated by the these transcription factors were measured to define their potential in vivo role in regulating postnatal metabolic adaptation.

\section{METHODS}

\section{Animal Preparation}

All studies were performed using fetal and newborn lambs of Dorset and Suffolk mixed breeding, obtained from a local source. The gestational ages were based on the induced ovulation technique as described elsewhere (19).

Anesthesia and surgical techniques of the fetal and newborn sheep have been described previously $(20,21)$. Briefly, after a 24-h fast of the pregnant ewe, general anesthesia was induced with a mixture of halothane (1\%), oxygen (33\%), and nitrous oxide (66\%). Under sterile conditions, the fetus was removed and the thorax opened. Fetal left and right ventricular free wall was isolated from animals at 93-95 d (95-d fetus) or 138-140 d (140-d fetus) gestation and immediately frozen in liquid nitrogen. Postnatal animals were handled in a fashion similar to the ewe although the fasting period was reduced. Tissue was obtained from 4-9 d (7-d newborn) and 7-8 wk (8-wk newborn) old animals. Animals of either sex were used.

All procedures were performed within the regulations of the Animal Welfare Act and the National Institutes of Health Guide for the Care and Use of Laboratory Animals and were approved by the University of Iowa Animal Care and Use Committee.

\section{Preparation of Ovine-Specific Partial cDNA Clones}

Primers for the each of the genes listed in Table 1 were designed from consensus regions of previously published sequences found in GenBank. For the genes listed, no ovine sequences were available. All PCR primers were designed using the Primer3 program (available at: http://www-genome.wi.mit.edu/cgibin/primer/primer3_www.cgi) and synthesized by Integrated DNA Technologies (Coralville, IA, U.S.A.). All PCR reactions were performed using the Invitrogen SuperScript One-Step ReverseTranscriptase (RT)-PCR for Long Templates (Invitrogen, Carlsbad, CA, U.S.A.). Starting RNA was obtained from fetal left ventricular free wall as described below. The PCR product was purified with the QIAQuick PCR Purification Kit (QIAGEN, Valencia, CA, U.S.A.), ligated into TopoPCR4 and cloned into Top 10 F' cells (Invitrogen). The plasmid was isolated and purified using QIAGEN Plasmid MaxiKit and sequenced to determine its orientation in the TopoPCR4 vector.

\section{Northern Blot Analyses}

$\boldsymbol{R N A}$ isolation. Total RNA was prepared from left or right ventricular free walls using a modification of the RNeasy Kit (QIAGEN), as previously described, quantitated spectrophotometrically, and stored at $-80^{\circ} \mathrm{C}(22)$. The pellet was dissolved in diethylpyrocarbonate-treated water, quantitated spectrophotometrically, and stored at $-80^{\circ} \mathrm{C}$ in ethanol until use.

Preparation of radiolabeled probes. Plasmids containing the partial cDNA clones were linearized and used to generate a labeled antisense probe using $\mathrm{d}-\left[{ }^{32} \mathrm{P}\right] \mathrm{UTP}$ and T3 (or T7) RNA polymerase as described previously (23).

Northern blot hybridization. The technique used for Northern blot hybridization has been described previously $(23,24)$. Briefly, a $1 \%$ agarose $/ 6.3 \%$ formaldehyde gel was prepared in $20 \mathrm{mM}$ 3-morpholinopropanesulfonic acid, $5 \mathrm{mM}$ sodium acetate, and $0.25 \mathrm{mM}$ EDTA at $\mathrm{pH}$ 7.0. Approximately $10 \mu \mathrm{g}$ of total RNA was applied to each well and electrophoresed overnight in a running buffer of $40 \mathrm{mM} 3$-morpholinopropanesulfonic acid, $10 \mathrm{mM}$ sodium acetate, and $0.5 \mathrm{mM}$ EDTA $(\mathrm{pH}$ 
Table 1. Consensus primers from published sequences, length of resulting ovine-specific cDNA, and the GenBank accession number for the resulting products

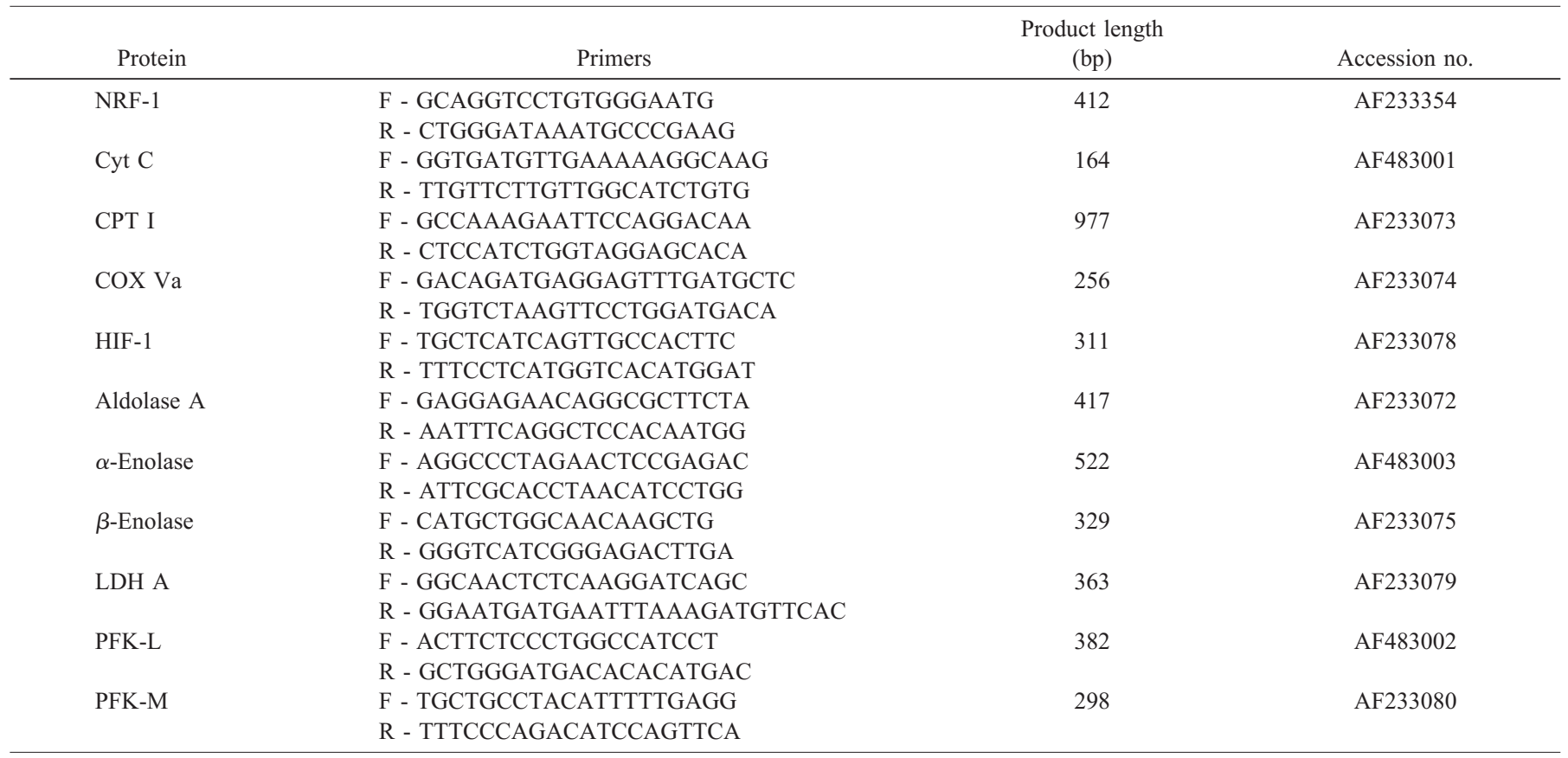

Cyt C, cytochrome $c$

7.0). The gels were stained with ethidium bromide and photographed as a reference for RNA sizing. RNA was then transferred to a $0.45-\mu \mathrm{m}$ Nytran membrane (Schleicher \& Schuell, Keene, NH, U.S.A.). The membranes were prehybridized for $1 \mathrm{~h}$ at $65^{\circ} \mathrm{C}$ in a solution containing $50 \%$ formamide, $5 \times \mathrm{SSPE}$ ( $875 \mathrm{mM}$ sodium chloride, $50 \mathrm{mM}$ sodium phosphate, $5 \mathrm{mM}$ EDTA), $5 \times$ Denhardt's reagent, $0.5 \%$ SDS, and $200 \mu \mathrm{g} / \mathrm{mL}$ denatured salmon sperm DNA. Hybridization was performed at $65^{\circ} \mathrm{C}$ for $12-18 \mathrm{~h}$ with the addition of $2 \times 10^{6} \mathrm{cpm} / \mathrm{mL}$ of radiolabeled probe. Four washes were performed at $65^{\circ} \mathrm{C}$ using three low-stringency washes $(1 \times \mathrm{SSPE}, 0.5 \% \mathrm{SDS})$ and one high-stringency wash $(0.1 \times$ SSPE, $0.5 \%$ SDS). Hybridization signals were quantitated using a phosphorimager (Amersham Pharmacia Biotech, Sunnyvale, CA, U.S.A.). Blots were then be stripped and rehybridized with ${ }^{32} \mathrm{P}$-labeled probe to the $18 \mathrm{~S}$ or $28 \mathrm{~S}$ subunit of ribosomal RNA. Signals from the $18 \mathrm{~S}$ or $28 \mathrm{~S}$ probed blots were used to correct for variable RNA loading. All Northern blots were done in triplicate for each probe.

\section{Quantitative Immunoblots}

A MAb to HIF- $1 \alpha$ and $-2 \alpha$ (Novus Biologicals, Littleton, CO, U.S.A.) and a polyclonal antibody raised to the carboxy terminus of NRF-1 (Santa Cruz Biotechnology, Santa Cruz, CA, U.S.A.) were obtained for immunoblot studies. Immunoblots were prepared as described previously (23). Briefly, left or right ventricular myocardium was homogenized in the presence of protease inhibitors including soybean trypsin inhibitor, leupeptin, and phenylmethanesulfonyl fluoride in $50 \mathrm{mM}$ Tris/10 mM EDTA/ $150 \mathrm{mM} \mathrm{NaCl} / 0.1 \%$ mercaptoethanol and then sonicated for $20 \mathrm{~s}$. After centrifugation, total protein of the supernatant was quantitated spectrophotometrically. Twenty micrograms of protein were separated by SDS-PAGE and transferred to a nitrocellulose membrane. Membranes were blocked with $5 \%$ nonfat milk protein for $1 \mathrm{~h}$ and then incubated in primary antibody overnight at $5^{\circ} \mathrm{C}$. After washes with EDTA $/ 0.5 \%$ Tween in PBS, incubation of secondary antibody conjugated with horseradish peroxidase at room temperature was performed for $1 \mathrm{~h}$. Detection of the secondary antibody using the Pierce SuperSignal Kit (Pierce Chemical, Rockford, IL, U.S.A.) was performed and used to expose Kodak XAR film (Eastman-Kodak, Rochester, NY, U.S.A.) at room temperature. Films were digitized and signals quantitated using NIH Image (National Institutes of Health, Bethesda, MD, U.S.A.). Serial protein dilutions were tested with each antibody to assure quantitated signals were in the linear range for added protein. Immunoblots for each antibody were done in triplicate.

\section{Statistics}

All data are expressed as mean \pm SEM. Comparisons between the four different ages groups were made using ANOVA. If significant overall differences were identified $(p<$ 0.05 ), pairwise comparisons were then made using Tukey's F test. All analyses were performed using StatView 5 for the Macintosh (SAS Institute, Cary, NC, U.S.A.).

\section{RESULTS}

\section{Ovine-Specific cDNA Probes}

Consensus primers were identified from published sequences for the genes encoding the transcription factors and metabolic enzymes that were investigated in this study. As described in the methods section, these primers were used to generate ovine-specific cDNA clones of the various genes. We have found that, despite significant interspecies homology of 
the genes that encode the metabolic enzymes, species-specific antisense probes improve the signal-to-noise of the Northern blots. For all the partial ovine genes sequenced for the current study, homology between sheep and human sequences ranged from $86 \%$ to $96 \%$ at the nucleotide level and between $86 \%$ and $99 \%$ at the amino acid level. The gene that was least conserved at the nucleotide level was aldolase A (86\%), whereas CPT I was least conserved at an amino acid level $(86 \%)$ in ovine myocytes.

\section{HIF-1 $\alpha$ and -2 $\alpha$ and Glycolytic Enzymes}

A dramatic decline in HIF- $1 \alpha$ protein levels was seen in the postnatal heart (Fig. 1). HIF-1 $\alpha$ protein, present in fetal right and left ventricular myocardium, was undetectable as early as $7 \mathrm{~d}$ postnatally and remained absent at 8 wk. Steady-state mRNA levels of the gene encoding HIF- $1 \alpha$ also declined significantly in the left ventricle during late gestation and remained low postnatally. Significant post-transcriptional reg-

\section{Left Ventricle}
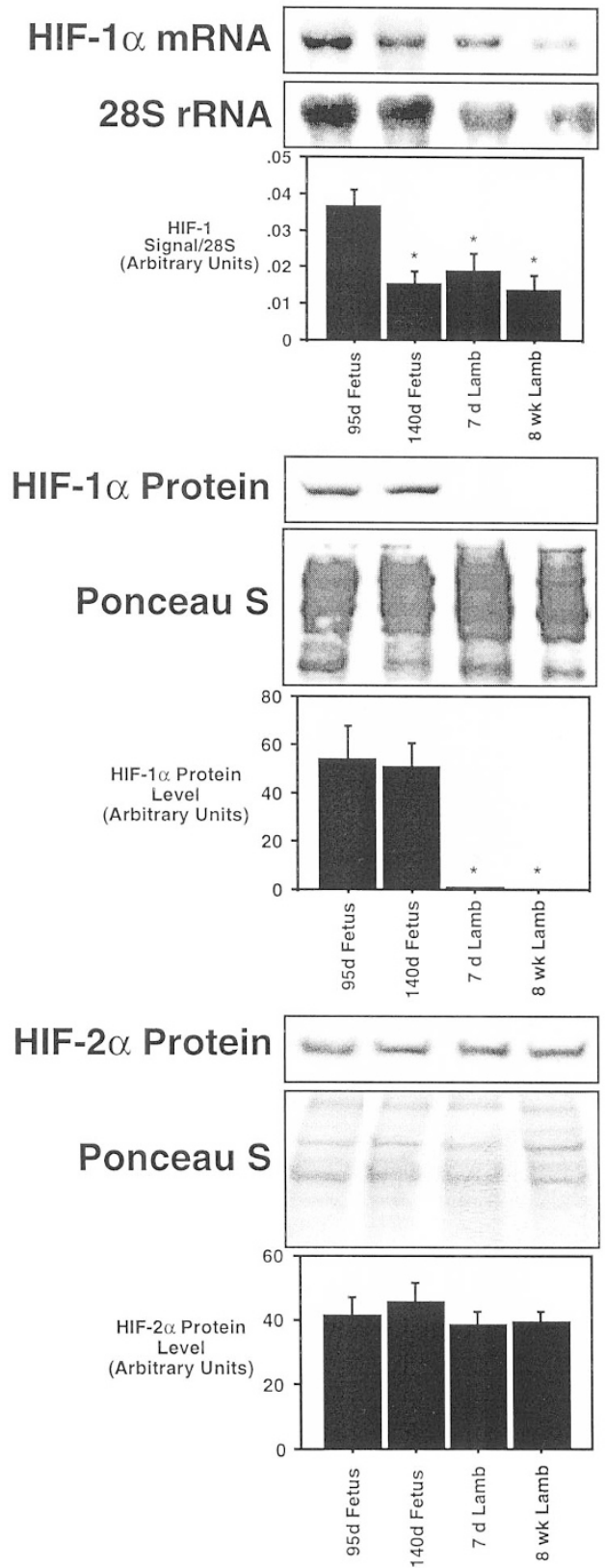
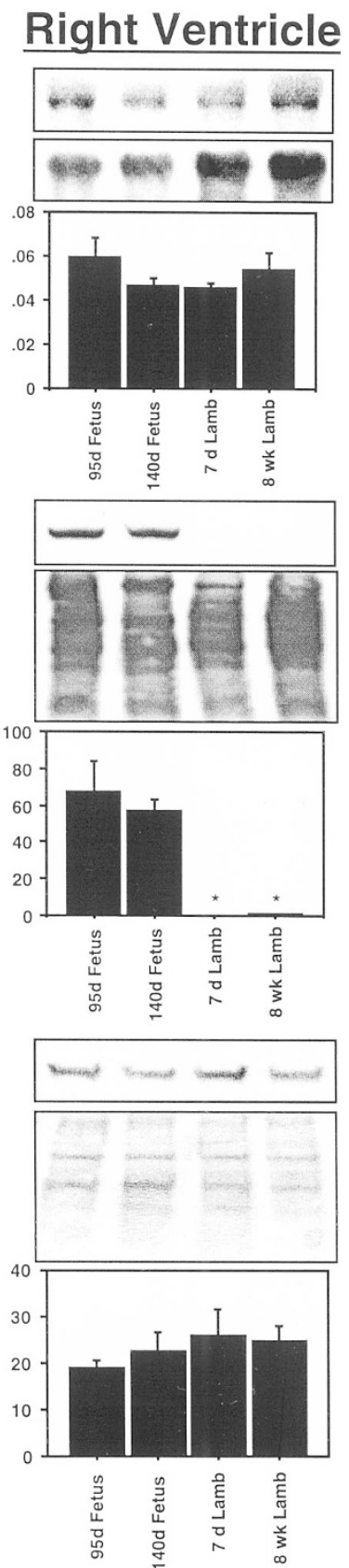

Figure 1. Steady-state mRNA and protein levels of HIF- $1 \alpha$ and $-2 \alpha$ in ovine left and right ventricular myocardium. Total myocardial RNA was isolated from ovine right or left ventricular free wall and separated by gel electrophoresis (top). Membranes were sequentially probed with an ovine-specific probe for HIF-1 $\alpha$ and $28 \mathrm{~S}$ rRNA and the resulting radioactive signal quantitated to determine the abundance of RNA. HIF- $1 \alpha$ signal was normalized to the $28 \mathrm{~S}$ signal. Total cardiac protein was prepared and separated by SDS-PAGE (bottom panels). Membranes were stained with Ponceau S to assure equal protein loading. HIF- $1 \alpha$ and $-2 \alpha$ protein levels were detected using standard immunoblot techniques and the resulting fluorescence signal quantitated by densitometry. All graphs are mean with error bars indicating the SEM ( $n=5$ for each age except $n=3$ for 7-d and 8-wk and HIF-2 $\alpha$ immunoblot groups). ${ }^{*} p<0.05$ vs 95 -d fetus for Northern blot studies (top) and $p<0.05$ vs $95-\mathrm{d}$ and 140-d fetus for immunoblots (bottom). 
ulation was demonstrated in the right ventricle, where stable mRNA levels were found at all four time points studied (Fig. 1). In contrast to the postnatal decline in HIF- $1 \alpha$ protein levels, HIF- $2 \alpha$ protein detected by immunoblot remained unchanged at the four time points studied (Fig. 1).

Transcription of several genes encoding glycolytic enzymes has been shown to be regulated by HIF-1 $\alpha$ through an upstream binding site (4). Despite the presence of similar HIF- $1 \alpha$ binding domains upstream to both the $\alpha$-enolase and aldolase A genes, differences were found in their postnatal expression (Fig. 2). Whereas steady-state mRNA levels of aldolase A were found to increase postnatally, $\alpha$-enolase mRNA levels fell in parallel to HIF-1 $\alpha$ protein levels. Isoenzyme specificity of HIF- $1 \alpha$ was confirmed by examining $\beta$-enolase expression. As shown in Figure 2, $\alpha$ - and $\beta$-enolase mRNA levels diverged with $\beta$-enolase expression, increasing significantly in both the right and left ventricular postnatally.

Figure 3 shows the steady-state mRNA levels of LDH A and PFK-L and PFK-M. In both ventricles, LDH A and PFK-L declined during the late gestation and postnatal periods, reaching significant reductions at the postnatal time points compared with the 95-d fetal myocardium (Fig. 3). As others have demonstrated $(25,26)$, the muscle isoform of PFK increased significantly throughout gestation in both ventricles and postnatally.

\section{NRF-1 and Mitochondrial Enzymes}

Postnatally, greater mitochondrial number and complexity of the inner mitochondrial membrane accompanies the increase in aerobic myocardial metabolism $(2,27)$. The regulation of these processes is just beginning to be understood and, as discussed above, may be significantly affected by NRF-1. Interestingly, the current study found a general decline in steady-state mRNA levels of NRF-1 and NRF-1 protein in both left and right ventricular myocardium throughout gestation and postnatally (Fig. 4). The highest levels of both NRF-1 mRNA and protein were found in the 95-d fetal heart.

In contrast to the developmentally regulated decline in NRF-1 in the right and left ventricle, nuclear genes encoding other mitochondrial proteins tended to increase throughout gestation and postnatally. Steady-state mRNA of three nuclear genes encoding mitochondrial proteins were quantitated; the results are summarized in Figures 5 and 6 . As shown by others, cDNA probes for the open reading frame of cytochrome $c$ hybridize to three separate bands on a Northern blot corresponding to sizes of roughly 700,1100 , and $1400 \mathrm{bp}$ in size (28). Our studies of left and right ventricular ovine myocardium found these three bands at all pre- and postnatal time points. At each time point in both ventricles, the 700-bp band represented the dominant of the three bands. The ratio of the 700-bp to 1400-bp signal stayed relatively constant at all four time points, although this ratio was approximately 10 in the left ventricle and 4 in the right ventricle, indicating less predominance of the 700-bp band in right ventricular myocardium. However, in both ventricles, a significant increase in all three bands was found postnatally (Fig. 5). Similar to cytochrome $c$, both muscle CPT I and COX Va showed significant increases
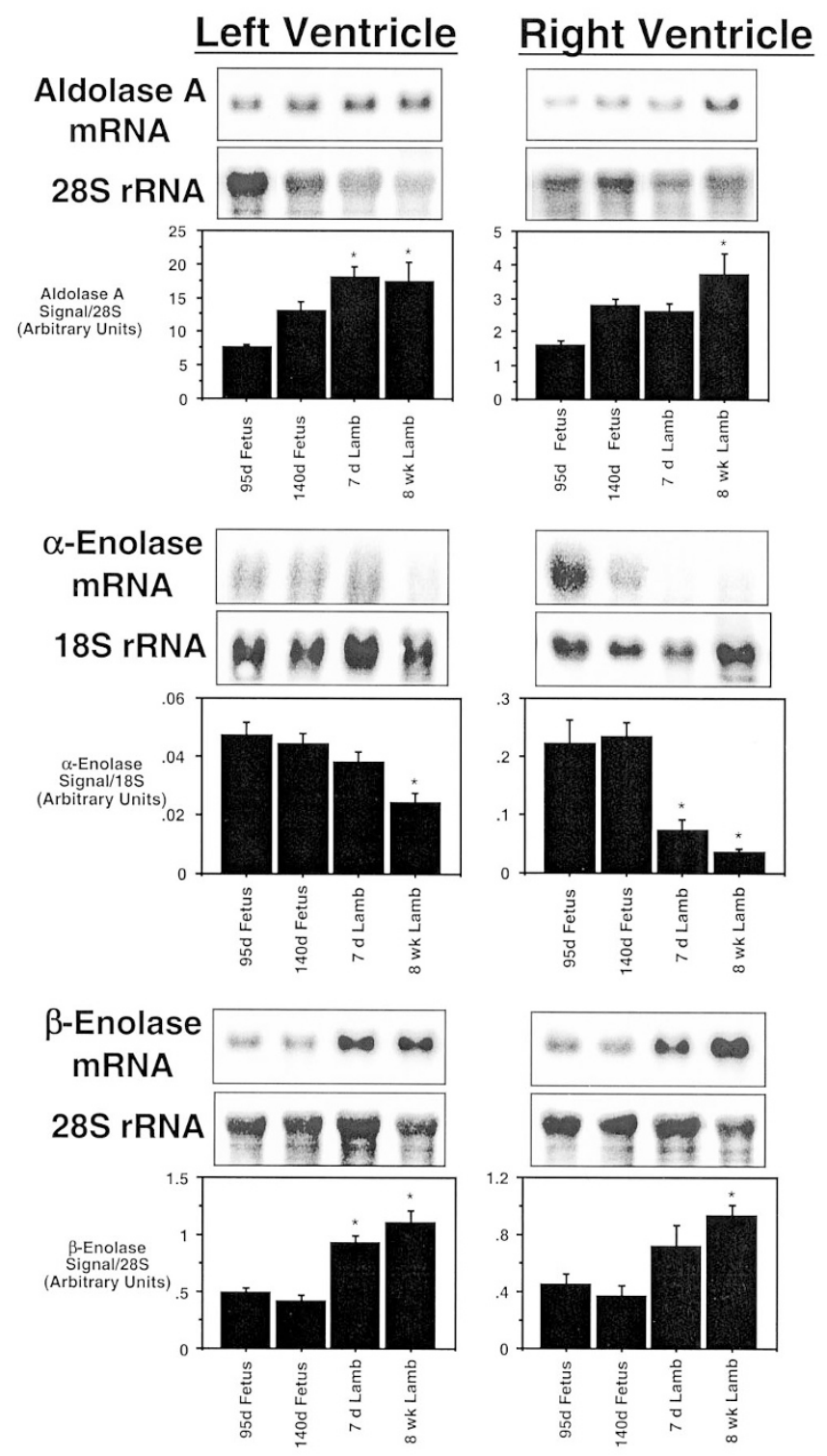

Figure 2. Steady-state mRNA levels of aldolase A and $\alpha$ - and $\beta$-enolase in ovine left and right ventricular myocardium. Total myocardial RNA was isolated from ovine right or left ventricular free wall and separated by gel electrophoresis. Membranes were sequentially probed with an ovine-specific probe for either aldolase A or $\alpha$ - and $\beta$-enolase and 18S or 28S rRNA and the resulting radioactive signal quantitated to determine the abundance of RNA. Aldolase $\mathrm{A}$ and $\beta$-enolase signals were normalized to the $28 \mathrm{~S}$ signal whereas the $\alpha$-enolase signal was normalized to $18 \mathrm{~S}$ rRNA levels. All graphs are mean with error bars indicating the SEM ( $n=5$ for each age group). ${ }^{*} p<0.05 v \mathrm{~s}$ 95-d fetus for aldolase A (top); * $p<0.05$ vs 95 -d and 140-d fetus for $\alpha$ - and $\beta$-enolase Northern blot studies (bottom).

in steady-state mRNA levels at postnatal time points compared with the fetal time points (Fig. 6).

\section{DISCUSSION}

These studies provide additional details of the complex regulatory scheme of cardiac metabolism that occurs during the perinatal period. Elegant genome analyses and in vitro assays have identified isolated cis-acting elements and transactivators of transcription of many genes encoding metabolic 


\section{Left Ventricle Right Ventricle}
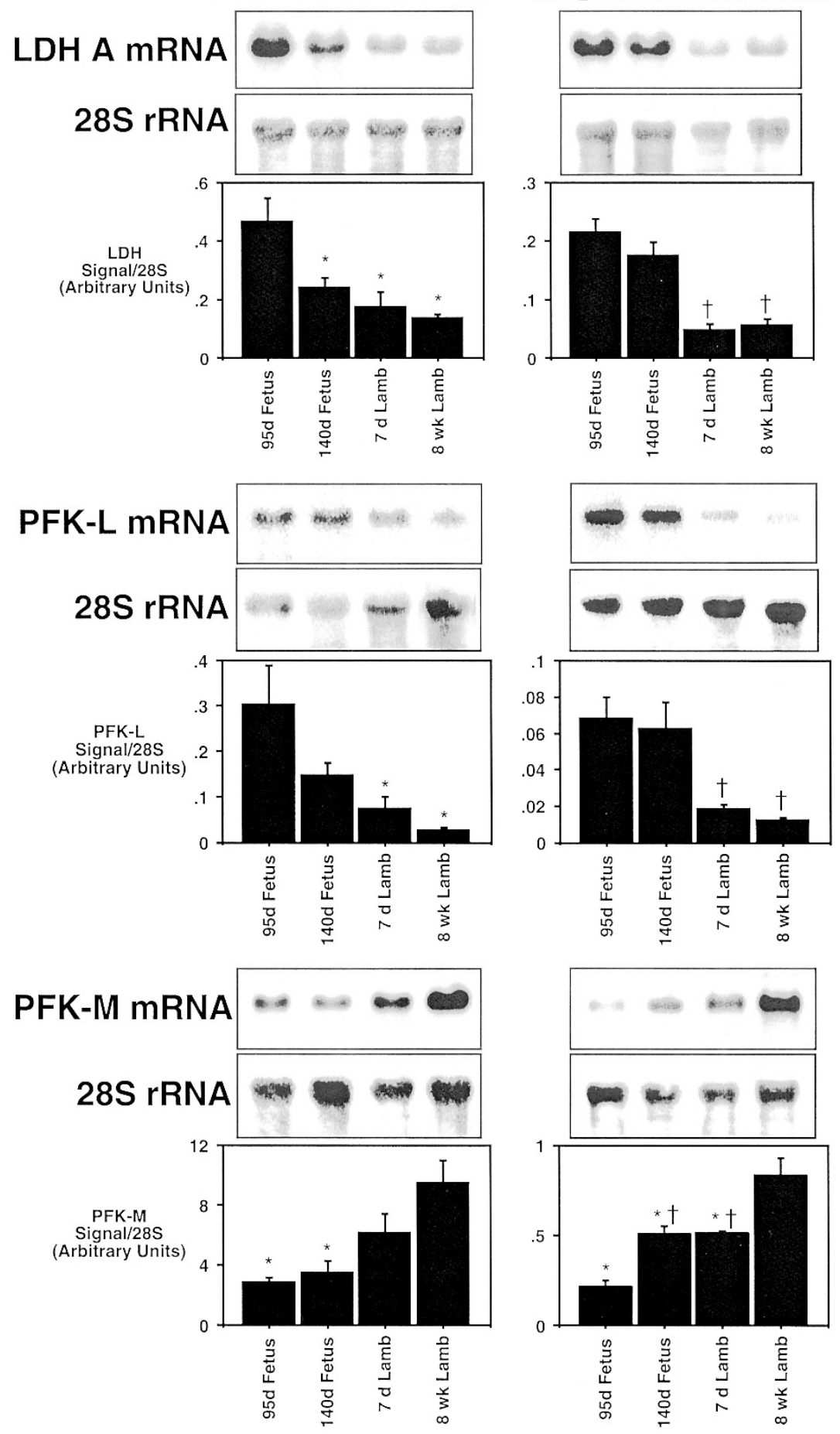

Figure 3. Steady-state mRNA levels of LDH A, PFK-L, and PFK-M in ovine left and right ventricular myocardium. Total myocardial RNA was isolated from ovine right or left ventricular free wall and separated by gel electrophoresis. Membranes were sequentially probed with an ovine-specific probe for either LDH A, PFK-L, or PFK-M and 28S rRNA and the resulting radioactive signal quantitated to determine the abundance of RNA. LDH A, PFK-L, and PFK-M signals were normalized to the $28 \mathrm{~S}$ signal. All graphs are mean with error bars indicating the SEM ( $n=5$ for each age group). ${ }^{*} p<0.05 v s 95$-d fetus and $\dagger p<0.05$ vs 95-d and 140-d fetus for LDH A (top); ${ }^{*} p<0.05$ vs 95 -d fetus and $\dagger p<0.05 v s$ 95-d and 140-d fetus for PFK-L (middle); ${ }^{*} p<0.05 v s$ 8-wk newborn and $\dagger p<0.05$ vs 95 -d fetus for PFK-M (bottom).

enzymes. However, the complex interrelationships of these factors in vivo are relatively unknown. This study was undertaken to define the association between changes in three important transcription factors (HIF- $1 \alpha$ and $-2 \alpha$, and NRF-1) and the expression of metabolic genes before, and after, the fetalto-postnatal transition. Many of the physiologic adaptations of the heart during this period have been defined, making this interval an ideal model for exploring regulatory mechanisms 


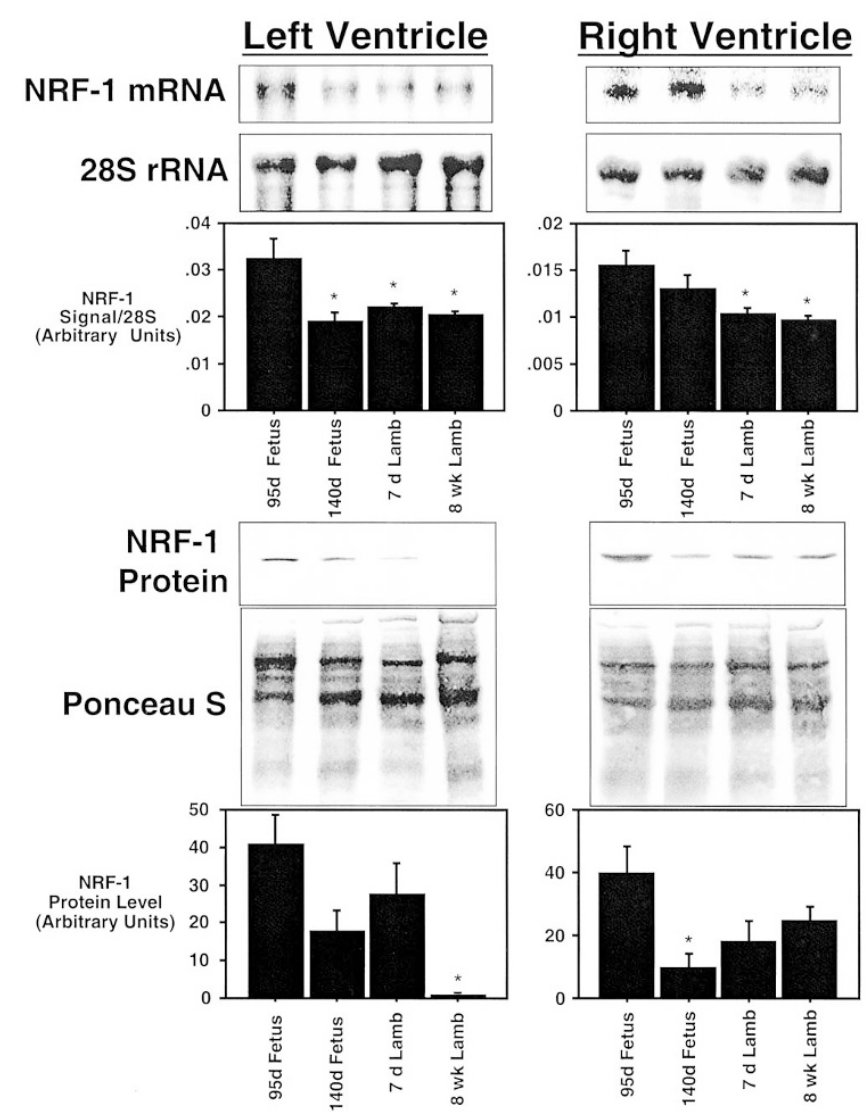

Figure 4. Steady-state mRNA and protein levels of NRF-1 in ovine left and right ventricular myocardium. Total myocardial RNA was isolated from ovine right or left ventricular free wall and separated by gel electrophoresis (top). Membranes were sequentially probed with an ovine-specific probe for NRF-1 and $28 \mathrm{~S}$ rRNA and the resulting radioactive signal quantitated to determine the abundance of RNA. NRF-1 signal was normalized to the $28 \mathrm{~S}$ signal. Total cardiac protein was prepared and separated by SDS-PAGE (bottom). Membranes were stained with Ponceau $\mathrm{S}$ to assure equal protein loading. NRF-1 protein levels were detected using standard immunoblot techniques and the resulting fluorescence signal quantitated by densitometry. All graphs are mean with error bars indicating the SEM $[n=5$ for each age group for Northern blot studies (top) and $n=3$ for each age group for immunoblot studies (bottom)]. ${ }^{*} p<0.05$ vs 95 -d fetus for Northern blot studies (top); ${ }^{*} p<0.05$ vs 95 -d fetus for immunoblot studies (bottom).

that may be important for both normal development and disease. Some of the associations identified between transcription factors and gene expression support in vitro data, whereas others indicate alternate control pathways dominate the regulation of gene expression in the intact heart.

\section{HIF-1 $\alpha$ and -2 $\alpha$ in Developing Myocardium}

Significant divergence was found between steady-state HIF- $1 \alpha$ mRNA levels and protein levels following the fetalto-postnatal transition (Fig. 1). This difference was most pronounced in the right ventricle, where no significant change in HIF- $1 \alpha$ mRNA levels was noted at the four time points studied despite a dramatic decline in HIF- $1 \alpha$ protein to undetectable levels in the postnatal myocardial samples. Steady-state HIF- $1 \alpha$ mRNA levels in the left ventricle declined significantly at the late gestation and postnatal time points compared with the early gestation samples, suggesting a level of transcriptional regulation of HIF-1 $\alpha$ at the mRNA level may occur in the left ventricle.

Previous studies have identified that regulation of HIF- $1 \alpha$ activity occurs at multiple levels. Initial investigations focused on the regulation of HIF- $1 \alpha$ at the transcriptional level $(6,29)$. The rapid degradation of the HIF- $1 \alpha$ protein and absence of DNA binding after a hypoxic-to-normoxic transition when HIF- $1 \alpha$ mRNA levels remained stable suggested that posttranscriptional mechanisms may dominate the regulation of HIF- $1 \alpha$ activity $(30,31)$. Indeed, elegant studies have demonstrated an oxygen-dependent domain within the HIF- $1 \alpha$ protein (32). Removal of the oxygen-dependent domain resulted in stable HIF- $1 \alpha$ levels whereas insertion of the domain into a stable protein conferred oxygen sensitivity (32). With the oxygen-dependent domain present in HIF- $1 \alpha$, degradation of HIF- $1 \alpha$ through the ubiquitin-proteasome system occurs when the protein is in an oxygen-rich environment $(32,33)$. The ubiquitin-proteasome pathway acts rapidly, degrading HIF- $1 \alpha$ in cells in culture with a protein half-life of approximately 5 $\min (32)$.

Although less extensively studied, HIF- $2 \alpha$, the recently identified analogue of HIF- $1 \alpha$, appears to be similarly regulated (9). Several cell lines demonstrated concomitant increases in HIF- $1 \alpha$ and HIF- $2 \alpha$ when exposed to a $1 \%$ oxygen environment. However, mRNA and protein levels of HIF- $1 \alpha$ and $-2 \alpha$ differed in several cell lines and tissues $(9,34)$.

Whereas the demonstration of post-transcriptional regulation of HIF- $1 \alpha$ and $-2 \alpha$ has been well defined in cell culture, limited studies in vivo have demonstrated the discordant relationship between HIF-1 $\alpha$ mRNA and protein levels. A generalized increase in HIF- $1 \alpha$ mRNA levels was found in brain, lung, and kidney of rats and mice maintained in a hypobaric chamber for as little as $30 \mathrm{~min}$ (29). Similarly, oxygendependent changes in HIF- $1 \alpha$ mRNA were found in ferret lung ventilated under hypoxic and normoxic conditions (35). In the ex vivo ferret lung preparation, HIF- $1 \alpha$ protein levels changed in parallel to the amount of mRNA measured in the tissue (35). Ischemic brain also demonstrated simultaneous changes in HIF- $1 \alpha$ mRNA and protein levels (36). To our knowledge, the current study is the first to measure both HIF- $1 \alpha$ mRNA and protein levels in myocardium from relatively hypoxic (fetal) and normoxic (postnatal) environments. The data presented in Figure 1 suggested that regulation may differ between the right and left ventricles, although the HIF- $1 \alpha$ protein levels vary in a similar fashion in both chambers, decreasing to undetectable levels postnatally.

\section{HIF-1 and Expression of Target Genes In Vivo}

Included among the genes with hypoxia response elements that bind HIF-1 are genes that encode several glycolytic enzymes (4). The developmental changes in the steady-state mRNA levels of six enzymes in the glycolytic reaction sequence, four of them described as containing cis-acting hypoxia response elements that bind HIF- $1 \alpha$ were examined. Transactivation by HIF-1 of the genes encoding aldolase A, $\alpha$-enolase, PFK-L, and LDH A has clearly been demonstrated 
Left Ventricle

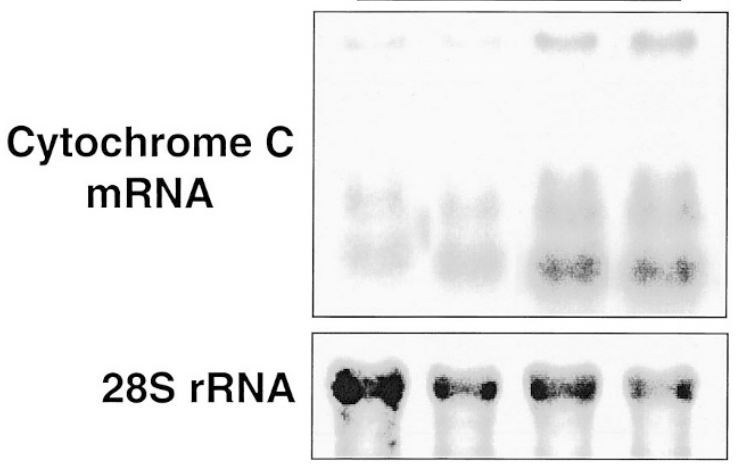

$\underline{\text { Right Ventricle }}$

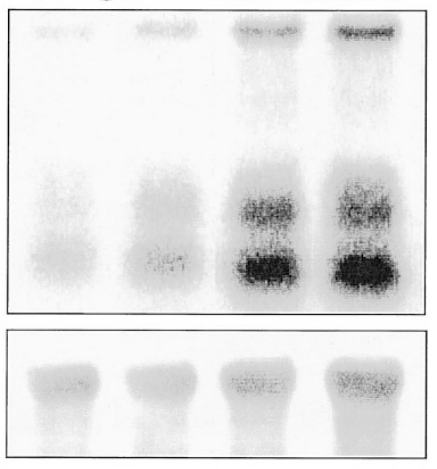

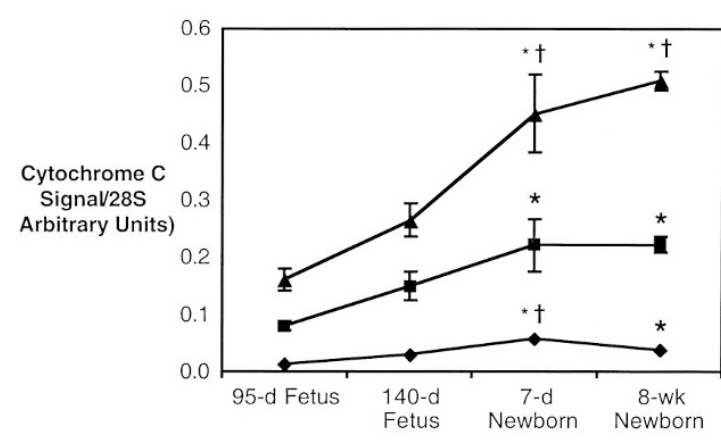

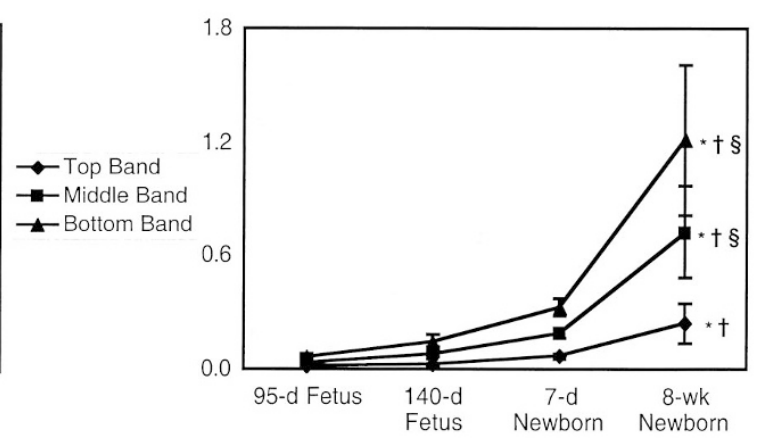

Figure 5. Steady-state mRNA levels of cytochrome $c$ in ovine left and right ventricular myocardium. Total myocardial RNA was isolated from ovine right or left ventricular free wall and separated by gel electrophoresis. Membranes were sequentially probed with an ovine-specific probe for cytochrome $c$ and $28 \mathrm{~S}$ rRNA and the resulting radioactive signal quantitated to determine the abundance of RNA. Three separate bands were identified with the cytochrome $c$-specific probe, quantitated and normalized to the $28 \mathrm{~S}$ signal. All points on the line graphs are mean with error bars indicating the SEM $\left(n=5\right.$ for each age group). ${ }^{*} p<0.05$ $v s$ 95-d fetus; $\dagger p<0.05$ vs 140-d fetus; $\S p<0.05$ vs 7-d newborn.

in cell culture $(12,13)$. In vivo, regulation of transcription of these genes appears to be more complex. We found myocardial $\alpha$-enolase, PFK-L, and LDH A mRNA levels followed a developmental pattern that paralleled the dramatic postnatal decline in HIF-1 $\alpha$ protein levels. Steady-state mRNA levels of aldolase A, $\beta$-enolase, and PFK-M, however, increased postnatally, suggesting influences from other regulatory mechanisms.

The complex regulation of these glycolytic enzymes was suggested by studies using embryonic stem cells lacking HIF- $1 \alpha(10,11)$. These studies demonstrated that HIF- $1 \alpha$ was necessary for constitutive expression of LDH A, PFK-L, and $\alpha$-enolase, although the two studies differed in their findings regarding aldolase A. In both studies, however, all four glycolytic gene products were present in the HIF-1 $\alpha$ null ES cells, indicating that alternate regulatory mechanisms exist.

The in vivo regulation of glycolytic enzymes during cardiac development has been examined over the years at both the total enzyme activity level as well as at the mRNA and protein levels. Identification of postnatal increases in PFK-M protein levels has been repeatedly shown $(25,26,37)$. These studies, however, have tended to demonstrate stable levels of L-type PFK protein and mRNA in the postnatal heart, in contrast to the current study. Although species differences may explain these disparate results, in vivo transactivation of the PFK-L gene by HIF-1 $\alpha$ has been shown in ischemic rat brain (36). Interesting postnatal changes in cardiac enolase activity and mRNA levels have also been observed. Late gestation and postnatal expression of the $\alpha$ - and $\beta$-subunits of enolase and their respective isoenzymes were examined in developing rat heart (38). Similar to our study, a significant postnatal decline in the $\alpha$-subunit at both the mRNA and protein levels was found.

\section{Postnatal Myocardial Development and Regulation by NRF-1}

Relative to the hypoxia-inducible factors HIF- $1 \alpha$ and $-2 \alpha$, regulation of NRF-1 expression and the role of NRF-1 in postnatal cardiac development is poorly understood. It is clear that after birth, the cardiac myocyte and mitochondria undergo rapid changes to adapt to the relatively oxygen-rich environment. Mitochondria become more numerous and the complexity of the inner mitochondrial membrane increases $(2,27)$. The oxidative capacity of the maturing mitochondria also increases, as evidenced by an increase in a number of enzyme complexes and subunits in the electron transport chain $(39,40)$. Concurrent regulation of expression of both nuclear and mitochondrial genes is essential to accomplish these developmental changes. NRF-1, through its regulation of nuclear genes and factors that regulate mitochondrial gene expression, may be important in orchestrating the postnatal maturational events $(14,16)$. Interestingly, both steady-state mRNA and protein levels of NRF-1 declined in the late gestation and postnatal ovine left and right ventricles (Fig. 4). Although these findings suggest important transcriptional regulation of NRF-1 expression in the developing heart, they are contrary to NRF-1 playing a direct role in 


\section{Left Ventricle}
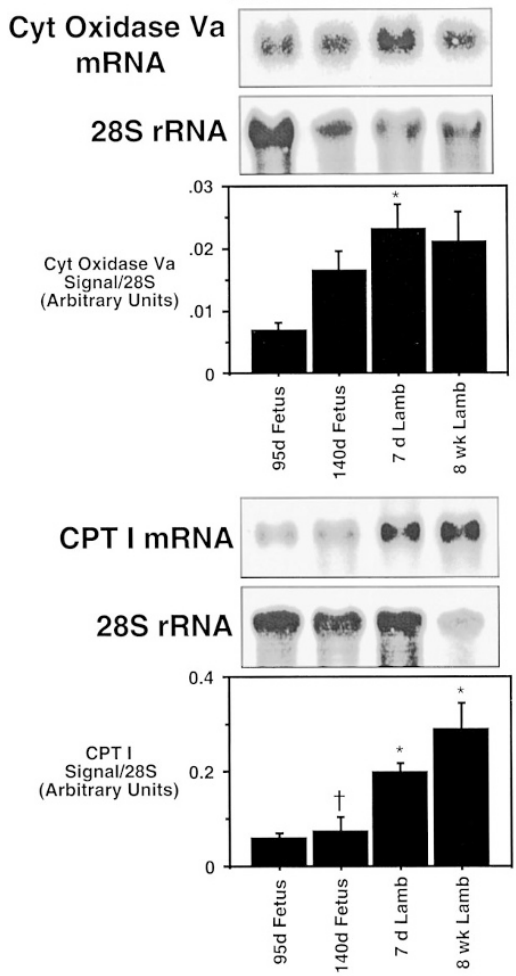
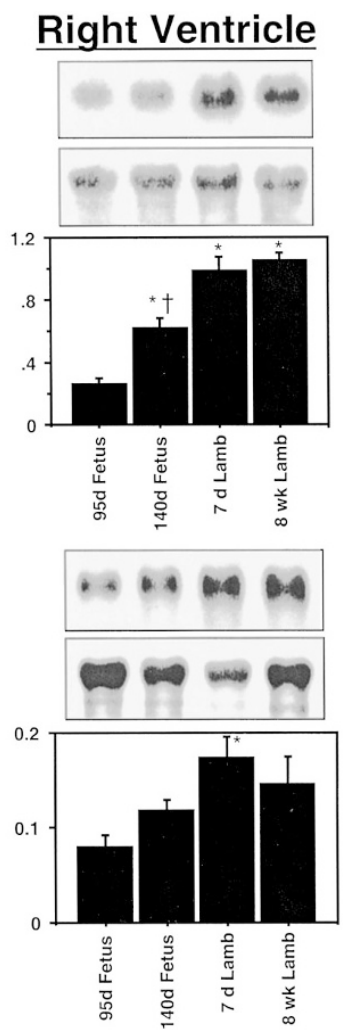

Figure 6. Steady-state mRNA levels of subunit Va of cytochrome oxidase (Cyt Oxidase $\mathrm{Va}$ ) and muscle CPT I in ovine left and right ventricular myocardium. Total myocardial RNA was isolated from ovine right or left ventricular free wall and separated by gel electrophoresis. Membranes were sequentially probed with an ovine-specific probe for either Cyt Oxidase Va or CPT I and 28S rRNA and the resulting radioactive signal quantitated to determine the abundance of RNA. Cyt Oxidase Va and CPT I signals were normalized to the $28 \mathrm{~S}$ signal. All graphs are mean with error bars indicating the SEM ( $n=5$ for each age group). $* p<0.05 v s 95$-d fetus and $\dagger p<0.05 v s$ 7-d and 8-wk newborn for Cyt Oxidase Va (top); ${ }^{*} p<0.05$ vs 95 -d fetus and $\dagger p<0.05$ vs 8-wk newborn for CPT I (bottom).

increasing transcription of genes such as cytochrome $c$, COX Va, or CPT I. Steady-state mRNA levels of each of these genes were found to increase significantly throughout gestation and postnatally.

Despite the lack of correlation between NRF-1 protein levels and changes in steady-state mRNA levels of the genes encoding mitochondrial enzymes in developing myocardium, the regulatory importance of NRF-1 has been demonstrated in other settings. Activation of a number of genes encoding contractile and metabolic proteins occurred after electrical stimulation of neonatal myocytes in culture $(18,41)$. Included in the genes that were up-regulated with electrical stimulation were cytochrome $c, \mathrm{COX} \mathrm{Va}$, and the liver isoform of CPT I. Preceding the increase in expression of these genes was an increase in NRF-1 mRNA. The decline in NRF-1 gene expression in the perinatal hearts suggests that alternative regulatory mechanisms influence mitochondrial maturation during this period or a novel "disinhibition" mechanism may be active.

It is clear that the regulation of expression of genes such as cytochrome $c$ is complex. The cytochrome $c$ gene has multiple cis-acting elements that include cAMP response elements (CRE) and Sp-1 and NRF-1 binding sites (16). Although in

electrically stimulated myocytes the NRF-1 binding site was the dominant regulatory domain of cytochrome $c$ mRNA levels, the importance of each of these sites in regulating expression of the cytochrome $c$ gene may depend on the physiologic trigger. The postnatal decrease in NRF-1 protein demonstrated in the current study suggested that either the CRE or Sp-1 sites may play a greater role in regulating cytochrome $c$ gene expression in the developing heart.

\section{CONCLUSIONS}

The perinatal heart provides an ideal model to explore mechanisms that regulate a variety of metabolic processes that are important not only for postnatal cardiac development but also for the adaptation to diseases such as myocardial infarction and hypertrophy. The current study made use of this model and examined the role of three important transcription factors in regulating the late gestation and postnatal changes in cardiac metabolism. Emerging from its relatively hypoxic in utero environment, the neonatal heart was found to rapidly decrease cellular content of HIF- $1 \alpha$ protein despite relatively stable HIF- $1 \alpha$ mRNA levels. HIF- $2 \alpha$ protein levels remained unchanged in the postnatal period. Changes in $\alpha$-enolase, PFK-L, and LDH A were consistent with the known role of HIF-1 in regulating expression of these genes. The regulatory importance of NRF-1 on nuclear encoded mitochondrial genes was not confirmed in the current study. The cytochrome $c$ gene, closely associated with NRF-1 regulation in other systems, did not follow the downward postnatal trend observed for NRF-1. As the list of genes with transcription factor binding sites for HIF- $1 \alpha$ and $-2 \alpha$, and NRF- 1 continues to expand, it will be important to continue to study the relationship between these vital transcription factors and the metabolic changes that occur in the developing heart.

\section{REFERENCES}

1. Lopaschuk GD, Collins-Nakai RL, Itoi T 1992 Developmental changes in energy substrate use by the heart. Cardiovasc Res 26:1172-1180

2. Smith H, Page E 1977 Ultrastructural changes in rabbit heart mitochondria during perinatal development. Dev Biol 57:109-117

3. Semenza GL, Agani F, Iyer N, Jiang BH, Leung S, Wiener C, Yu A 1998 Hypoxiainducible factor 1: from molecular biology to cardiopulmonary physiology. Chest 114(suppl):40S-45S

4. Semenza GL 2000 HIF-1: mediator of physiological and pathophysiological responses to hypoxia J Appl Physiol 88:1474-1480

5. Wang GL, Semenza GL 1993 General involvement of hypoxia-inducible factor 1 in transcriptional response to hypoxia. Proc Natl Acad Sci U S A 90:4304-4308

6. Wang GL, Jiang BH, Rue EA, Semenza GL 1995 Hypoxia-inducible factor 1 is a basic-helix-loop-helix-PAS heterodimer regulated by cellular $\mathrm{O}_{2}$ tension. Proc Natl Acad Sci U S A 92:5510-5514

7. Ema M, Taya S, Yokotani N, Sogawa K, Matsuda Y, Fujii-Kuriyama Y 1997 A novel bHLH-PAS factor with close sequence similarity to hypoxia-inducible factor 1alpha regulates the VEGF expression and is potentially involved in lung and vascular development. Proc Natl Acad Sci U S A 94:4273-4278

8. Tian H, McKnight SL, Russell DW 1997 Endothelial PAS domain protein 1 (EPAS1), a transcription factor selectively expressed in endothelial cells. Genes Dev 11:72-82

9. Wiesener MS, Turley H, Allen WE, Willam C, Eckardt KU, Talks KL, Wood SM, Gatter KC, Harris AL, Pugh CW, Ratcliffe PJ, Maxwell PH 1998 Induction of endothelial PAS domain protein-1 by hypoxia: characterization and comparison with hypoxia-inducible factor-1alpha. Blood 92:2260-2268

10. Iyer NV, Kotch LE, Agani F, Leung SW, Laughner E, Wenger RH, Gassmann M, Gearhart JD, Lawler AM, Yu AY, Semenza GL 1998 Cellular and developmental control of $\mathrm{O}_{2}$ homeostasis by hypoxia-inducible factor 1 alpha. Genes Dev 12:149162

11. Ryan HE, Lo J, Johnson RS 1998 HIF-1 alpha is required for solid tumor formation and embryonic vascularization. EMBO J 17:3005-3015 
12. Semenza GL, Roth PH, Fang HM, Wang GL 1994 Transcriptional regulation of genes encoding glycolytic enzymes by hypoxia-inducible factor 1. J Biol Chem 269:2375723763

13. Semenza GL, Jiang BH, Leung SW, Passantino R, Concordet JP, Maire P, Giallongo A 1996 Hypoxia response elements in the aldolase A, enolase 1, and lactate dehydrogenase A gene promoters contain essential binding sites for hypoxiainducible factor 1. J Biol Chem 271:32529-32537

14. Evans MJ, Scarpulla RC 1990 NRF-1: a trans-activator of nuclear-encoded respiratory genes in animal cells. Genes Dev 4:1023-1034

15. Virbasius CA, Virbasius JV, Scarpulla RC 1993 NRF-1, an activator involved in nuclear-mitochondrial interactions, utilizes a new DNA-binding domain conserved in a family of developmental regulators. Genes Dev 7:2431-2445

16. Scarpulla RC 1996 Nuclear respiratory factors and the pathways of nuclearmitochondrial interaction. Trends Cardiovasc Med 6:39-45

17. Virbasius JV, Scarpulla RC 1991 Transcriptional activation through ETS domain binding sites in the cytochrome $c$ oxidase subunit IV gene. Mol Cell Biol 11:56315638

18. Xia Y, Buja LM, Scarpulla RC, McMillin JB 1997 Electrical stimulation of neonatal cardiomyocytes results in the sequential activation of nuclear genes governing mitochondrial proliferation and differentiation. Proc Natl Acad Sci U S A 94:1139911404

19. Jennings JJ, Crowley JP 1972 The influence of mating management on fertility in ewes following progesterone-PMS treatment. Vet Res 90:495-498

20. Segar JL, Hajduczok G, Smith BA, Merrill DC, Robillard JE 1992 Ontogeny of baroreflex control of renal sympathetic nerve activity and heart rate. Am J Physiol 263:H1819-H1826

21. Segar J, Bedell K, Page W, Mazursky J, Nuyt A-M, Robillard J 1995 Effect of cortisol on gene expression of the renin-angiotensin system in fetal sheep. Pediatr Res 37:1-6

22. Bonham M, Danielpour D 1996 Improved purification and yields of RNA by RNeasy. Biotechniques 21:57-60

23. Scholz TD, Koppenhafer SL, TenEyck CJ, Schutte BC 1998 Ontogeny of malate/ aspartate shuttle capacity and gene expression in cardiac mitochondria. Am J Physiol 274:C780-C788

24. Scholz T, Koppenhafer S, TenEyck C, Schutte B 1997 Developmental regulation of the $\alpha$-glycerophosphate shuttle in porcine myocardium. J Mol Cell Cardiol 29:1605-1613

25. Thrasher JR, Cooper MD, Dunaway GA 1981 Developmental changes in heart and muscle phosphofructokinase isozymes. J Biol Chem 256:7844-7848

26. Dunaway GA, Kasten TP, Kolm P 1986 Alteration of 6-phosphofructo-1-kinase isozyme pools during heart development and aging. J Biol Chem 261:17170-17173

27. Sordahl LA, Crow CA, Kraft GH, Schwartz A 1972 Some ultrastructural and biochemical aspects of heart mitochondria associated with development: fetal and cardiomyopathic tissue. J Mol Cell Cardiol 4:1-10
28. Scarpulla RC, Wu R 1983 Nonallelic members of the cytochrome $c$ multigene family of the rat may arise through different messenger RNAs. Cell 32:473-482

29. Wiener CM, Booth G, Semenza GL 1996 In vivo expression of mRNAs encoding hypoxia-inducible factor 1. Biochem Biophys Res Commun 225:485-488

30. Huang LE, Arany Z, Livingston DM, Bunn HF 1996 Activation of hypoxia-inducible transcription factor depends primarily upon redox-sensitive stabilization of its alpha subunit. J Biol Chem 271:32253-32259

31. Wenger RH, Kvietikova I, Rolfs A, Gassmann M, Marti HH 1997 Hypoxia-inducible factor-1 alpha is regulated at the post-mRNA level. Kidney Int 51:560-563

32. Huang LE, Gu J, Schau M, Bunn HF 1998 Regulation of hypoxia-inducible factor lalpha is mediated by an $\mathrm{O}_{2}$-dependent degradation domain via the ubiquitinproteasome pathway. Proc Natl Acad Sci U S A 95:7987-7992

33. Salceda S, Caro J 1997 Hypoxia-inducible factor 1alpha (HIF-1alpha) protein is rapidly degraded by the ubiquitin-proteasome system under normoxic conditions. Its stabilization by hypoxia depends on redox-induced changes. J Biol Chem 272:22642 22647

34. Talks KL, Turley H, Gatter KC, Maxwell PH, Pugh CW, Ratcliffe PJ, Harris AL 2000 The expression and distribution of the hypoxia-inducible factors HIF-1alpha and HIF-2alpha in normal human tissues, cancers, and tumor-associated macrophages. Am J Pathol 157:411-421

35. Yu AY, Frid MG, Shimoda LA, Wiener CM, Stenmark K, Semenza GL 1998 Temporal, spatial, and oxygen-regulated expression of hypoxia-inducible factor-1 in the lung. Am J Physiol 275(4 Pt 1):L818-L826

36. Bergeron M, Yu AY, Solway KE, Semenza GL, Sharp FR 1999 Induction of hypoxia-inducible factor-1 (HIF-1) and its target genes following focal ischaemia in rat brain. Eur J Neurosci 11:4159-4170

37. Mhaskar Y, Dunaway GA 1996 Alteration of 6-phosphofructo-1-kinase subunit protein, synthesis rates, and mRNA during rat neonatal development. Mech Ageing Dev 86:161-172

38. Keller A, Rouzeau JD, Farhadian F, Wisnewsky C, Marotte F, Lamande N, Samuel JL, Schwartz K, Lazar M, Lucas M 1995 Differential expression of alpha- and beta-enolase genes during rat heart development and hypertrophy. Am J Physiol 269(6 Pt 2):H1843-H1851

39. Marin-Garcia J, Baskin LS 1989 Human cytochrome $c$ oxidase during cardiac growth and development. Pediatr Cardiol 10:212-215

40. Bonne G, Seibel P, Possekel S, Marsac C, Kadenbach B 1993 Expression of human cytochrome $c$ oxidase subunits during fetal development. Eur J Biochem 217:10991107

41. Xia Y, Buja LM, McMillin JB 1998 Activation of the cytochrome $c$ gene by electrical stimulation in neonatal rat cardiac myocytes. Role of NRF-1 and c-Jun. J Biol Chem 273:12593-12598 